\title{
Villaseñor Velarde y otros vs. Guatemala ${ }^{1}$
}

Corte Interamericana de Derechos Humanos

Sentencia (resumen)

Publicado: 5 de febrero de 2019

E1 5 de febrero de 2019 la Corte Interamericana de Derechos Humanos (en adelante también "Corte", "Corte Interamericana" o "Tribunal") dictó una Sentencia, mediante la cual declaró responsable internacionalmente al Estado de Guatemala por la violación de los derechos a la integridad personal, a las garantías judiciales y a la protección judicial en perjuicio de María Eugenia Villaseñor Velarde (en adelante "señora Villaseñor" o “jueza”). Asimismo, la Corte determinó que el Estado no es responsable por la violación del derecho a la integridad personal en perjuicio de Beatriz Eugenia Villaseñor Velarde, Francis Antonio Villaseñor Velarde y Rosa Antonieta Villaseñor Velarde, quienes son, respectivamente, hija, hermana y hermano de la señora Villaseñor. Tampoco consideró responsable a Guatemala por la violación al derecho a la protección de la honra y de la dignidad respecto de ninguna de las personas nombradas.

\section{Hechos}

Los hechos del caso tuvieron lugar desde la década de 1990 hasta 2013, cuando la señora Villaseñor se desempeñó como jueza, ocupando distintos cargos. Realizó actos destacados en el marco de su actividad, en particular, entre 1991 y 1997. Entre ellos, la actuación en causas judiciales de trascendencia pública.

Distintas fuentes indican que, durante la década de 1990 y al menos hasta 2012, existió en Guatemala una situación de inseguridad respecto de operadores de justicia, quienes podían verse expuestos a diversos actos de intimidación o agresión relacionados con su función, comprometiéndose la vigencia de la independencia judicial, sin que hubiera una respuesta efectiva del Estado para

\footnotetext{
${ }^{1}$ Corte Interamericana de Derechos Humanos. (2019). Caso Villaseñor Velarde y otros vs. Guatemala [sentencia resumida]. Recuperado de http://www.corteidh.or.cr/docs/casos/articulos/resumen_374_esp.pdf
} 
garantizar sus derechos y los de sus familiares. En ese marco, hubo distintas indicaciones sobre actos intimidatorios contra la señora Villaseñor.

Así, antes de septiembre de 1994 la jueza denunció amenazas directas (inclusive la amenaza o el intento de secuestro de su hija), daños intencionales a sus bienes, intentos de acceder a su domicilio, entre otros hechos. También puso en conocimiento de las autoridades que el 29 de agosto un agente asignado a su seguridad fue retenido, golpeado, drogado e interrogado sobre actividades de la jueza, y que quienes lo retuvieron le dijeron que iban a matar a las personas que habitaban la residencia de ella.

También se indicó que entre 1995 y 2013 sucedieron otros hechos, tales como manifestaciones de funcionarios o notas de prensa contrarias a la jueza o sus actuaciones, actos de vigilancia, expresiones públicas de militares contra la señora Villaseñor, recepción de correos electrónicos injuriosos, robo de diversas pertenecías de la jueza o sus familiares.

\section{Fondo}

La Corte advirtió que el caso se refiere a posibles presiones externas sobre la actividad judicial. Por ello, se relaciona con un aspecto central del Estado de Derecho: la independencia judicial, que es un principio ampliamente reconocido, un objetivo principal de la separación de los poderes públicos y uno de los pilares básicos de las garantías del debido proceso, indispensable para la protección de los derechos fundamentales. La independencia judicial abarca la garantía contra presiones externas; el Estado debe adoptar acciones para evitar que personas $\mathrm{u}$ órganos ajenos al Poder Judicial o sus integrantes cometan actos de injerencias indebidas sobre éstos.

Ahora bien, la Corte consideró que no había elementos suficientes para considerar algunos de los hechos señalados en el caso, en sí mismos, como presiones indebidas sobre la jueza, por constituir un ejercicio de la libertad de expresión, denuncia o planteos judiciales, respecto de los cuales no había base suficiente para considerarlos lesivos de los derechos de la víctima. Además, notó que no podía determinar, el eventual carácter ilícito de algunos de los hechos 
intimidatorios denunciados al ser considerados en forma individual. Asimismo, entendió que no podía atribuir responsabilidad al Estado por la participación directa de agentes estatales.

Sin perjuicio de lo anterior, el caso involucró el señalamiento de una sucesión o conjunto de hechos que podían estar relacionados y evidenciar la existencia de presiones externas respecto de la actividad judicial de la señora Villaseñor. En particular, hechos anteriores a septiembre de 1994 habrían implicado graves circunstancias de intimidación. Quedó acreditado que el Estado tuvo conocimiento de todos los hechos señalados como intimidatorios por diversos medidos, inclusive distintas presentaciones y denuncias efectuadas por la jueza en el ámbito interno.

Por ello, Guatemala debía realizar actuaciones para garantizar los derechos de la señora Villaseñor Velarde, por lo que resultó procedente examinar las medidas de seguridad e investigación adoptadas.

La Corte observó que el Estado, entre 1994 y 2013, brindó seguridad a la jueza y sus familiares durante un tiempo cercano a 18 años, haciéndolo en forma prácticamente constante a partir de 1996, mediante la asignación de personal policial para su protección. Por ello, cumplió con su deber de protección de modo efectivo.

En cuanto a acciones de investigación respecto de los hechos denunciados por la jueza, la Corte encontró que no consta actividad estatal respecto de: a) el hecho de 29 de agosto de 1994; b) indicaciones sobre amenazas directas anteriores a septiembre de ese año; c) una denuncia de amenazas de julio de 1994, cuyo expediente fue extraviado; d) dos denuncias realizadas en 1997, y e) una orden policial de 2001 para que se investigaran amenazas por parte de militares. Además, Guatemala inició una investigación por "amenazas" respecto a una denuncia de julio de 2005, pero la actividad investigativa fue escasa y las actuaciones duraron más de 12 años sin llegar a resultados. Por esa razón la Corte concluyó que Guatemala no investigó de modo efectivo hechos del caso.

El Tribunal resaltó que el cumplimiento de la obligación de investigar puede ser un medio para garantizar derechos sustantivos y que, además, quien se considere víctima de violaciones a sus derechos tiene derecho de acceder a la justicia para que se cumpla dicho deber. Dado que en el caso se indicó una situación de riesgo prolongada en el tiempo y relacionada con la actividad de la señora Villaseñor, 
el cumplimiento del deber de investigar podía ser relevante para la desactivación o merma del riesgo y para garantizar la independencia judicial. La Corte, considerando lo dicho y distintos elementos de prueba, entendió razonable asumir que el incumplimiento del deber de investigar generó en la señora Villaseñor una situación de incertidumbre y angustia que afectó su integridad personal.

El Tribunal, por el contrario, no encontró violado el derecho a protección de la honra y de la dignidad, pues, como se señaló, no analizó individualmente diversos actos de expresión y, además, en relación con algunos señalamientos puntuales: a) notó que la Corte Suprema, después de un procedimiento, constató que la señora Villaseñor no tenía relación con un proceso judicial respecto del cual se la había acusado de actos de corrupción, y b) como ya quedó asentado, el Estado investigó el origen de un correo electrónico de noviembre de 2007 que profería acusaciones contra la jueza.

Por último, la Corte destacó que la conducta estatal indebida se restringió al deber de investigar, y que no era posible trasladar la conclusión sobre la afectación a la integridad personal de la jueza a sus familiares. Además, no son atribuibles al Estado las circunstancias que pudieron afectarlos directamente. Por ello, no se declaró una violación a la integridad personal ni a la protección de la honra y de la dignidad en perjuicio de la hija, la hermana y el hermano de la señora Villaseñor.

En definitiva, por la falta de actuaciones efectivas para investigar los hechos, la Corte concluyó que Guatemala incumplió su deber de garantizar el derecho a la integridad personal de la señora Villaseñor, que se vio afectado en relación con su independencia judicial. Asimismo, menoscabó sus derechos a las garantías judiciales y protección judicial. Por ende, la Corte declaró que Guatemala violó, en perjuicio de la señora María Eugenia Villaseñor Velarde, los artículos 5.1, 8.1 y 25.1 de la Convención Americana sobre Derechos Humanos, en relación con el artículo 1.1 del mismo tratado.

\section{Reparaciones}

La Corte ordenó al Estado, como medidas de reparación: i) publicar la Sentencia de la Corte Interamericana y su resumen, y ii) pagar la cantidad fijadas en la 
Sentencia por concepto de daño inmaterial. Además determinó que Guatemala debe reintegrar sumas de dinero erogadas por el Fondo de Asistencia Legal de Víctimas de la Corte Interamericana, que fue aplicado en el caso. 